\title{
Attitudes of Medical Students Regarding Cancer Pain Management: Comparison Between Pre- and Post-Lecture Test Findings
}

\author{
Sasikaan Nimmaanrat*, Maliwan Oofuvong
}

\begin{abstract}
Background: Medical practitioners' attitudes have a significant impact on quality of care for cancer pain patients. This study was conducted to determine if being given a lecture concerning cancer pain and its management could improve the attitudes of medical students. Materials and Methods: A comparative study was conducted in 126 fifth-year medical students. Each student completed a pretest consisting of 3 questions about attitudes toward the optimal use of analgesics and 5 questions about attitudes toward prescribing opioids. Then they were given a 1.5-hour lecture, immediately following which they completed a post-test with the same questions. Results: Analysis with either comparison between groups or by matching, the post-test showed significantly more positive attitudes $(\mathbf{p}<0.05)$ of the medical students in all 3 questions about optimal use of analgesics and 4 out of 5 questions about prescription of opioids. The post-test results showed significantly more negative attitudes concerning the most appropriate stage for patients with severe pain to receive maximal doses of analgesics. Conclusions: Conservative attitudes, especially concerns about addiction, have been associated with a reluctance in many physicians to prescribe opioids. This study found that cancer pain education can help to improve medical student attitudes. However, fear of addiction and tolerance was still evident so emphasis of this particular issue during a lecture is essential. Providing appropriate information by means of a lecture can improve the attitudes of medical students regarding cancer pain management. However, more information should be given to lessen fear of addiction and tolerance.
\end{abstract}

Keywords: Attitudes - cancer pain - cancer pain management - medical students

Asian Pac J Cancer Prev, 16 (17), 7453-7456

\section{Introduction}

Even though prevalence and intensity of cancer pain vary due to setting of study and population, it is still undoubtedly undertreated (Fairchild, 2010) and continues to be a considerable worldwide health issue (Kaki, 2011). Numerous factors have been identified as barriers to effective cancer pain management including patients, families, medical providers and health care policies (Jacobsen et al., 2009). It has been demonstrated that patients with advanced cancer commonly had wrong knowledge regarding opioids, a belief that palliative care was particularly for end-stage patients, and concerns about homecare, mainly the family burden and reactions to abrupt changes (Akiyama et al., 2012). Kim M, et al. have found that a large number of young clinicians had negative attitudes and insufficient knowledge about management of cancer pain (Kim et al., 2011). Yanjun S, et al. have found similar results that clinicians showed inadequate basic knowledge and incorrect concepts of morphine usage for cancer pain therapy (Yanjun et al., 2010). Other studies also revealed indifferent outcomes (Alvarez et al., 2010; Breuer et al., 2011; Liao et al., 2013).
Niemi-Murola $L$ et al. Have found positive attitudes of medical students' towards cancer pain management (Niemi-Murola et al., 2007). On the other hand, Kaki $\mathrm{AM}$, has demonstrated poor knowledge and negative attitudes of medical students' about cancer pain (Kaki, 2011). Nimmaanrat $S$ et al. Have found mixed results in regard to attitudes and knowledge of cancer pain and its management (Nimmaanrat et al., 2008, Nimmaanrat et al., 2009, Nimmaanrat et al., 2010).

Education given to health care personnel has been found to improve both attitudes and knowledge (Bennett et al., 2011). On the patients' side, it has also been revealed that a psychoeducational intervention offered a useful foundation for educating them in terms of cancer pain management (Rustoen et al., 2012).

We conducted this study to evaluate whether providing a lecture about cancer pain and its management could improve medical students' attitudes by using pretest and posttest questionnaires.

\section{Materials and Methods}

This comparative study was conducted in 126 fifthyear (the year before the final year) medical students. Each 
of them completed the pretest consisting of 3 multiplechoice questions about attitudes toward the optimal use of analgesics for treating cancer pain [1. At what stage would you feel it is appropriate to receive maximal doses of analgesics for severe pain?, 2. How would you rate the level of patient demand for pain medication? and 3 . Reasons for a cancer patient who requests increasing amounts of analgesic to control pain] and 5 questions (to rate from strongly disagree to strongly agree) about attitudes toward prescribing opioids [1. When prescribing opioids, I would be very careful in the control of dosage and frequency for the prevention of drug tolerance and addiction, 2. The opioid dosage patients receive should be much lower than the required dosage for the prevention of drug tolerance, 3 . When I prescribe opioids, I would insinuate to patients or their relatives that opioids are not good drugs and they had better bear the pain as much as possible, 4 . When I find patients who bear severe pain and refuse the morphine injection, I would encourage their behavior and 5. I do not like to prescribe opioids, because respiratory depression is a very severe side effect] Then they were provided a 1.5-hour lecture with contents regarding cancer pain and its management. Immediately following the lecture, they completed the post-test with the same questions as the pretest.

Data were analyzed using either comparison between groups or by matching. The P-value of $<0.05$ is regarded as significant.

\section{Results}

Analysis with either comparison between groups or

Table 1. Comparison between pretest and post-test regarding medical students' attitudes toward the optimal use of analgesics for cancer pain management (Percentage)

\begin{tabular}{|c|c|c|c|}
\hline Questions & Pretest $(\%)$ & Post-test (\%) & P-value \\
\hline \multicolumn{4}{|c|}{ 1. At what stage would you feel it is appropriate to receive maximal doses of analgesics for severe pain? } \\
\hline A. Prognosis $<1$ month & 15.9 & 15.9 & \multirow[t]{5}{*}{$<0.001$} \\
\hline B. Prognosis $1-3$ months & 38.9 & 16.7 & \\
\hline C. Prognosis 4-6 months & 25.4 & 20.6 & \\
\hline D. Prognosis $7-12$ months & 10.3 & 9.5 & \\
\hline E. Prognosis $13-24$ months & 9.5 & 37.3 & \\
\hline \multicolumn{4}{|c|}{ 2. How would you rate the level of patient demand for pain medication? } \\
\hline A. Too much & 46 & 29.6 & \multirow[t]{3}{*}{0.028} \\
\hline B. About right & 41.3 & 53.6 & \\
\hline C. Too little & 12.7 & 16.8 & \\
\hline \multicolumn{4}{|c|}{ 3. When a cancer patient requests increasing amounts of analgesic to control pain, this usually indicates } \\
\hline A. Patient is psychologically addicted & 6.3 & 0.8 & \multirow[t]{6}{*}{$<0.001$} \\
\hline B. Patient has developed tolerance to drug & 26.2 & 39.7 & \\
\hline C. Increased pain & 48.4 & 56.3 & \\
\hline D. Increased anxiety & 12.7 & 1.6 & \\
\hline E. Increased depression & 5.6 & 1.6 & \\
\hline F. Need more attention & 0.8 & 0 & \\
\hline
\end{tabular}

Table 2. Comparison between pretest and post-test regarding medical students' attitudes toward opioid prescribing

\begin{tabular}{|c|c|c|c|c|c|c|c|c|c|c|c|}
\hline \multirow[t]{2}{*}{ Questions } & \multicolumn{2}{|c|}{$\begin{array}{c}\text { Strongly } \\
\text { disagree }(\%)\end{array}$} & \multicolumn{2}{|c|}{$\begin{array}{c}\text { Disagree } \\
(\%)\end{array}$} & \multicolumn{2}{|c|}{$\begin{array}{l}\text { No } \\
\text { comment } \\
(\%)\end{array}$} & \multicolumn{2}{|c|}{ Agree $(\%)$} & \multicolumn{2}{|c|}{$\begin{array}{c}\text { Strongly } \\
\text { agree }(\%)\end{array}$} & \multirow[t]{2}{*}{ P-value } \\
\hline & Pre & Post & Pre & Post & Pre & Post & Pre & Post & Pre & Post & \\
\hline $\begin{array}{l}\text { 1. When prescribing opioids, I would be very } \\
\text { careful in the control of dosage and frequency } \\
\text { for the prevention of drug tolerance and } \\
\text { addiction. }\end{array}$ & 0.8 & 7.9 & 2.4 & 9.5 & 2.4 & 1.6 & 52.4 & 31.7 & 42.0 & 49.3 & $<0.001$ \\
\hline $\begin{array}{l}\text { 2. The opioid dosage patients receive should } \\
\text { be much lower than the required dosage for } \\
\text { the prevention of drug tolerance. }\end{array}$ & 24.6 & 70.6 & 55.6 & 25.4 & 12.6 & 1.6 & 5.6 & 1.6 & 1.6 & 0.8 & $<0.001$ \\
\hline $\begin{array}{l}\text { 3. When I prescribe opioids, I would } \\
\text { insinuate to patients or their relatives that } \\
\text { opioids are not good drugs and they had } \\
\text { better bear the pain as much as possible. }\end{array}$ & 43.7 & 85.7 & 46.8 & 11.1 & 3.2 & 2.4 & 6.3 & 0.8 & 0 & 0 & $<0.001$ \\
\hline $\begin{array}{l}\text { 4. When I find patients who bear severe pain } \\
\text { and refuse the morphine injection, I would } \\
\text { encourage their behavior. }\end{array}$ & 18.4 & 61.1 & 52.8 & 28.6 & 17.6 & 4.0 & 8.8 & 6.3 & 2.4 & 0 & $<0.001$ \\
\hline $\begin{array}{l}\text { 5. I do not like to prescribe opioids, because } \\
\text { respiratory depression is a very severe side } \\
\text { effect. }\end{array}$ & 11.2 & 46.4 & 63.2 & 49.6 & 8.0 & 1.6 & 17.6 & 2.4 & 0 & 0 & $<0.001$ \\
\hline
\end{tabular}


by matching, the post-test showed significantly more positive attitudes $(\mathrm{p}<0.05)$ of the medical students in all 3 questions about the optimal use of analgesics and in 4 out of 5 questions about prescription of opioids. (Table 1 and 2) The post-test showed significantly more negative attitudes concerning the fear of addiction and tolerance. Higher percentage of the medical students in the post-test $(49.3 \%)$ showed strong agreement that they would be very careful to control dosage and frequency of opioid prescription for prevention of addiction and tolerance in comparison to the pretest (42.0\%). (Table 2)

\section{Discussion}

We performed this study because our previous surveys demonstrated mixed results of medical students' attitudes for cancer pain and its management (Nimmaanrat et al., 2008, Nimmaanrat et al., 2009, Nimmaanrat et al., 2010). From this study, we have found significantly more positive attitudes from the post-test of the medical students' in all 3 questions about optimal use of analgesics and 4 of 5 questions about prescription of opioids. However, the post-test showed significantly more negative attitudes concerning the fear of opioid addiction and tolerance.

It has clearly been demonstrated that medical providers are one of the major barriers for insufficient cancer pain management. The most obvious clinician-related barriers are inadequate knowledge, inadequate outlines of pain assessment and inadequate opioid prescription (Jacobsen et al., 2009).

Our results have shown that education can improve attitudes of the medical students. These are in accordance with other studies using various methods in various kinds of learners. Murinson BB, et al. designed and delivered a new course in pain using foundation-level knowledge to the first year medical students and found that a four-day course integrating sessions with pain consultants, pain knowledge and design-built contents was a successful educational technique to make emotional skills better (Murinson et al., 2011). Sloan et al. (2001) used a cancer pain Objective Structured Clinical Examination (OSCE) developed by a multidisciplinary group of pain specialists to assess medical students' clinical competence and summaries that the cancer pain OSCE was a valuable performance-based instrument to evaluate individual skills in cancer pain management (Sloan et al., 2001).

Pelayo-Alvarez et al. (2013) have demonstrated that general practitioners who participated in an online palliative care education program for 18 months significantly increased their knowledge (Pelayo-Alvarez et al., 2013). Xhixha et al. (2013) have found that barriers to the use of opioids in general practitioners (using the Barrier Questionnaire II - BQ II) were significantly lower after the one-day seminar (8 hours) (Xhixha et al., 2013).

Studies in other health care providers have also shown similar results. Machira et al. (2013) have found pain management knowledge and attitude deficits at baseline in nurses. After receiving pain management program, they showed better knowledge and attitudes at the first and second follow-up assessments (Machira et al., 2013). Gustafsson et al. (2013) have demonstrated that a theory- based educational intervention can effectively change nurses' knowledge and attitudes in terms of cancer pain therapy (Gustafsson et al., 2013).

Lasch et al. (2002) have proposed optimal integration of pain management into curriculum in order to transfer knowledge for appropriate student knowledge and attitudes (Lasch et al., 2002).

Apart from health care personnel, use of a knowledge and attitude survey (Pain Experience Scale - PES), as part of a psychoeducational intervention offered effective patient education for cancer pain management (Rustoen et al., 2012).

It has been mentioned that professionalization process of medical education may reinforce negative attitudes (Weinstein et al., 2000). However, previously mentioned studies have shown that various means of interventions lead to improvement of knowledge and attitudes. Our study has revealed the same results except fear of opioid addiction and tolerance. We have found significantly higher percentage of the medical students with fear of opioid addiction and tolerance on the posttest. A belief that opioids are addictive leads to insufficient opioid prescription resulting in poor cancer pain control (Bennett et al., 2011). Under this circumstance, education emphasizing on this particular issue is fundamental for improving medical students' attitudes to lessen fear of addiction and tolerance.

Giving a lecture to medical students can improve their attitudes toward the optimal use of analgesics and opioid prescription for management of cancer pain. However, fear of opioid addiction and tolerance remains as a significant problem. Thus a lecture focusing on this particular issue is essential to improve their attitudes and lessen their unhealthy fear.

\section{References}

Akiyama M, Takebayashi T, Morita T, et al (2012). Knowledge, beliefs, and concerns about opioids, palliative care, and homecare of advanced cancer patients: a nationwide survey in Japan. Support Care Cancer, 20, 923-31.

Alvarez YE, Sanchez CAR, Martinez FC, et al (2010). Professional survey on knowledge and clinical patterns of pain management in Spanish medical oncology. Clin Transl Oncol, 12, 819-24.

Bennett MI, Flemming K, Closs SJ (2011). Education in cancer pain management. Curr Opin Support Palliat Care, 5, $20-4$.

Breuer B, Fleishman SB, Cruciani RA, et al (2011). Medical oncologists' attitudes and practice in cancer pain management: a national survey. J Clin Oncol, 29, 4769-75.

Fairchild A (2010). Under-treatment of cancer pain. Curr Opin Support Palliat Care, 4, 11-5.

Gustafsson M, Borglin G (2013). Can a theory-based educational intervention change nurses' knowledge and attitudes concerning cancer pain management? A quasi-experimental design. BMC Health Serv Res, 13, 328.

Jacobsen R, Liubarskiene Z, Moldrup C, et al (2009). Barriers to cancer pain management: a review of empirical research. Medicina, 45, 427-33.

Kaki AM (2011). Medical students' knowledge and attitude toward cancer pain management in Saudi Arabia. Saudi Med J, 32, 628-32.

Kim M,Park HG, Park EC, et al (2011). Attitude and knowledge 
of physicians about cancer pain management: young doctors of South Korea in their early career. Jpn J Clin Oncol, 41, 783-91.

Lasch K, Greenhill A, Wilkes G, et al (2002). Why study pain? A qualitative analysis of medical and nursing faculty and students' knowledge of and attitudes to cancer pain management. J Palliat Med, 5, 57-71.

Liao Z, Hao J, Guo Y, et al (2013). Assessment of cancer pain management knowledge in Southwest China: a survey of 259 physicians from small city and county hospitals. J Palliat Med, 16, 692-5.

Machira G, Kariuki H, Martindale L (2013). Impact of an educational pain management programme on nurses' pain knowledge and attitudes in Kenya. Int J Palliat Nurs, 19, 341-6.

Murinson BB, Nenortas E, Mayer RS, et al (2011). A new program in pain medicine for medical students: integrating core curriculum knowledge with emotional and reflective development. Pain Med, 12, 186-95.

Niemi-Murola L, Nieminen JT, Kalso E, et al (2007). Medical undergraduate students' belief attitudes toward pain - how do they mature? Eur J Pain, 11, 100-6.

Nimmaanrat S, Phungrassami T, Prechawai C (2008). Medical Students' Knowledge and Attitudes toward Cancer Pain and Its Management. Songkla Med J, 26, 423-9.

Nimmaanrat S, Prechawai C (2009). Interns' Knowledge and Attitudes regarding Cancer Pain and Cancer Pain Management. Songkla Med J, 27, 491-501.

Nimmaanrat S, Prechawai C, Phungrassami T (2010). Cancer Pain and Its Management: A Survey on Interns' Knowledge, Attitudes and Barriers. Palliat Care Res Treat, 4, 11-7.

Pelayo-Alvarez M, Perez-Hoyos S, Agra-Varela Y (2013). Clinical effectiveness of online training in palliative care of primary care physicians. J Palliat Med, 16, 1-9.

Rustoen T, Valeberg BT, Kolstad E, et al (2012). The Pro-Self ${ }^{\odot}$ pain control program improves patients' knowledge of cancer pain management. J Pain Symptom Manage, 44, 321-30.

Sloan PA, Plymale MA, Johnson M, et al (2001). Cancer pain management skills among medical students: the development of a cancer pain objective structured clinical examination. $J$ Pain Symptom Manage, 21, 298-306.

Weinstein SM, Laux LF, Thornby JI, et al (2000). Medical students' attitudes toward pain and the use of opioid analgesics: implications for changing medical school curriculum. South Med J, 93, 472-8.

Xhixha A, Rama R, Radbruch L (2013). Reducing the barriers to pain management in Albania: results from an educational seminar with family doctors. J Palliat Med, 16, 758-61.

Yanjun S, Changli W, Ling W, et al (2010). A survey on physician knowledge and attitudes towards clinical use of morphine for cancer pain treatment in China. Support Care Cancer, 18, 1455-60. 